\title{
INSTITUTIONAL QUALITY. HUMAN CAPITAL AND INDUSTRIAL SECTOR GROWTH IN ECOWAS
}

\author{
Patrick OLOGBENLA* \\ Obafemi Awolwo University, Nigeria
}

\begin{abstract}
The industrial sector has been identified as a tool for effective economic diversification among developing countries but major challenges of the sector have been the institutional and human capital in these economies. Consequently, the need to re-assess the relationship among the three is pertinent. The study investigates empirically, the impacts of institutional quality and human capital on the industrial sector growth of the ECOWAS. The methodology adopted is quantitative with the use of panel data analysis. Findings from the analysis show that both human capital and institutional quality in the ECOWAS have not supported industrial growth significantly. However, the result shows that macroeconomic variables such as inflation rate and exchange rate have the largest effect on the growth of the industrial sector of ECOWAS. The study used ECOWAS that has not been used by any of the previous authors and the economic bloc is in dire need of economic diversification. It is recommended that ECOWAS countries should improve on their institutional quality and human capital development for them to be effective in promoting the growth of their industrial sector.
\end{abstract}

JEL classification: J24, J38, L60;

Keywords: Industrial Sector Growth, Institutional Quality, Human Capital

\section{Introduction}

The role of industrial development in sustainable economic growth cannot be over emphasized. It leads to inclusive growth by facilitating job creation and raising productivity in agriculture, where most of the population in low income regions like Economic Community of West African States ECOWAS is employed. A vibrant industrial sector is necessary to engage the outputs of the agricultural sector and utilize them for the overall economic development of the region. However, this

*Corresponding author. Address: Obafemi Awolowo University, Nigeria, ologbenlapatrick@gmail.com. ORCID 0000-0001-8127-3155. 
process can be pursued by improving the business climate, providing better technical training, and exploiting new technologies (Ranis, 1973). Solow (1956) maintained that long-term economic growth is dependent on technical progress, which he assumed to be exogenous. The developed countries have long embraced high technological innovation as evidenced in their high capital-labour ratio.

However, ECOWAS with the huge population and vast human capital, the industrial sector of the region remains largely underdeveloped when compared to other similar regions across the globe. According to (Abubakar, Kassim, \& Yusoff, 2015) the growing population of ECOWAS which is supposed to be a blessing by breeding a virile human capital that can promote the industrial sector growth appears to be the greatest undoing of the industrial sector development in Nigeria. In 2016, the population growth rate in the ECOWAS was $34 \%$ with Nigeria taking the leading role in this astronomical rise. On the contrary, at this same period, the growth rate of the industrial sector in the big countries like Nigeria, Senegal and Ghana fell by $2.5 \%$, $2.1 \%$ and $1.2 \%$ respectively (Ajide, 2014), (Keho, 2018)

One of the major factors identified by the International Labour Organization ILO (2015) and World Bank (2016) as very germane to facilitating the synergy between industrial growth and human capital is the government policy and this is where the role of institutions comes in. It is believed that with good institution, human capital can easily translate to positive industrial growth. The quality of institutions across Sub Sahara Africa countries and Africa at large has been a major source of concern to stakeholders in the industrial sectors. The latest corruption index shows that many African countries have been recording upward movements especially the leading countries in the ECOWAS region. The corruption index which is one of the widely used indicators of government quality in the literatures shows that on the average corruption index rose in the ECOWAS from $24 \%$ in 2015 to about $27 \%$ in 2018 (Nurudeen, Karim, Zaini, \& Aziz, 2015), (Lavallée \& Roubaud, 2019). These data show that the control of corruption in the ECOWAS leaves much to desired and it also speaks volume of the weak institutional quality of the region. But could this, with the poor human capital, have been responsible for the gloomy performance of the industrial sector as opined by ILO and World Bank? The answer to this question is the focus of this study.

Some gaps have been identified in the literature regarding this study. A host of the past studies have focused on either the impact of human capital on industrial sector or impact of institutional quality on industrial sector, thus, making it difficult to study the joint effects of both on industrial sector in a singular study (Dawson, 1998; Nguyen, 2020; Desmet, Greif, \& Parente, 2020; Haltiwanger, Lane, \& Spletzer, 2019). In addition, many of the past studies used corruption alone to proxy institutional quality. However, with the emergence of more indicators like government effectiveness narrowing the definition of institution quality to only corruption control might be myopic. Consequently, this study will apart from using control of corruption as an indicator of institutional quality, will also add government effectiveness in order to have a broader perspective of institutional quality unlike previous studies.

The aim of this study is to investigate the impacts of human capital and institutional quality on the industrial growth of the ECOWAS. 12 out of the 16 members are focused on in this study due to non-availability of data on Cape Verde, Guinea and Guinea Bissau. However, the 12 members covered in this study include Nigeria, which is the largest economy, Ivory Coast, Ghana and Senegal among others. 
These 12 countries control about 95\% of the GDP of ECOWAS thus making it justifiable to use them to represent ECOWAS.

\section{Methodology}

\section{Research Design}

This aspect of the research discusses the research method in general. It includes the theoretical framework, the model specification, sources of data, estimating techniques among others

\section{Theoretical framework: Endogenous growth theory}

The theory used for this study is extracted from the endogenous growth theory precisely the Lucas version of the growth theory which is explained in the Lucas model of 1988. According to Lucas (1988), it is the investment in human capital and not physical capital that has spillover effects that increase the level of technology. For firm i, the output based on Lucas position take the form

$$
\mathbf{Y}_{i}=\mathrm{A}\left(\mathrm{k}_{\boldsymbol{i}}\right) \cdot\left(\mathrm{H}_{i}\right) . \mathrm{e} \quad \mathbf{H}
$$

Where $A=$ technical Coefficient

$\mathrm{K}_{i}=$ physical input

$\mathrm{H}_{i}=$ human capital input

$\mathrm{H}=$ the organization/economy's average level of Human capital

$\mathrm{e}=$ degree of external effects from human capital to each firm's productivity.

In this Lucas model, constant return to scale is assumed for the model to thrive and technology is endogenously provided as a side effect of investment decision by firms. From the point of view of the user, technology is regarded as a public good thus making it possible to treat the firms as price takers. The Lucas model predicts easy arrival of equilibrium as the price-taking firms are on the same page with many other firms under perfect competitive market situation.

According to Lucas (1988), human capital is sometimes suggested as a potential engine of growth and education and training is an important factor in this regard. In addition, Ojapinwa (2016) among others opined that the organizational/ economy average of human capital is strongly influenced by institutional quality. Therefore, a modification of Lucas model can be presented as follows:

$$
Y_{i}=f\left(K_{i}, H_{i}, e_{i}, I_{i}\right)
$$

Where, $Y_{i}$ is the output, $\mathrm{K}_{i}$ is physical input, $H_{i}$ is human capital, $e_{i}$ is the degree of external effects from human capital to each firm's productivity, $I_{i}$ is the institutional quality which has influence on the behavior of human capital and e represents other external or control variables in the model. 


\section{Model Specification}

For the objective of the study, a model that follows equation 2 is formulated. In addition, the model is modified to include some of the important indicators of institutional quality such as political instability, corruption control, rule of law index and government effectiveness. Again, since industrial development is of more importance to this study than industrial output growth, $Y_{i}$ is therefore, expressed in real term hence it becomes real growth rate of the industrial sector in SSA and the model for this study is specified thus:

$$
y_{i, t}=f\left(k_{i, t} \cdot h_{i, t} \cdot I_{i, t} \cdot e_{i, t}\right)
$$

The linear form of equation 2 is presented in equation 3

$$
\log y_{i, t}=\log \delta+\theta \log k_{i, t}+\varphi \log h_{i, t}+\beta \log I_{i, t}+\sigma \log e_{i, t}+\varepsilon
$$

In equation $3, y_{i, t} I s$ the real growth rate of the industrial sector of country $i$ at period t. $\mathrm{k}_{\mathrm{i}, \mathrm{t}}$ is the physical capital ( gross capital formation) of country $\mathrm{i}$ at period t. $h_{i, t}$ is the human capital index of country $i$ at period t. $I_{i, t}$ is the institution quality ( that is control of corruption and government effectiveness) of country $i$ at period $t$. Lastly, $e_{i, t}$ are other control variables that are very germane to the development of the Sub-Saharan African countries. In this study, the variables to be included are inflation rate and exchange rate.

\section{Sources of Data}

Data on industrial sector growth are collected from the Global Economics Database 2018, while the corruption index which is proxy for institution quality is extracted from the World Bank Tables, 2018. Human capital Index is extracted from PENN WORLD TABLES, 2019. The remaining control variables are also sourced from the World Bank.

\section{Estimation Techniques}

The study adopts panel data regression analysis to analyze the relationship between human capital, institutional quality and economic development in SubSaharan Africa. The panel data procedure starts from the panel unit root test as it is important that all the variables included in the panel model are stationary.

\section{Panel Unit Root Test}

The conventional unit root test is no longer popular as a result of the advantages inherent in the panel unit root test. Levin, Lin and Chu (1995), (Choi, 2001), (Breitung \& Das, 2005) demonstrated a considerable improvement in the power of Unit Root tests when using panel data other than the univariate testing procedures. The panel unit root test explores the data characteristics of the panel before proceeding to the panel co-integration test. The idea is to test for stationarity of each variable used in the study. According to Engel and Granger (1997), a variable may not be stationary but a linear combination of the non-stationary variables may be stationary hence the need for co-integration. 
Another method of panel unit test to be adopted for this study is Im, Pesaran and Shin (IPS) test. The test has been proven to be suitable in verifying stationarity of variables in panel data (Im, Pesaran and Shin, 2003), (Maddala and Wu, 1999). The basic IPS specification is given as:

$$
\Delta Y_{i, t}=a Y_{i, t-1}+\sum_{j=1 Y i j}^{P i} \Delta Y_{i, t-j}+\beta_{0}+\beta_{1 t}+\beta_{1} x_{i, t}+\varepsilon_{i, t}
$$

Where $\beta$ o is the constant, $x_{i, t}$ represents the explanatory variables, $\Delta Y_{i, t}$ is the explained variable, $\beta_{1 \mathrm{t}}$ is a time trend and $P$ is the required lag length. The null hypothesis to be tested for the IPS is $\mathrm{H}_{0}: \alpha_{1}=0$ for all "i"s while the alternative hypothesis is $\mathrm{H}_{1}: \alpha_{i}<0$, for at least one $\mathrm{i}$. The lag lengths are selected using the Akaike Information Criterion (Hoechle, 2007; Ng \& Perron, 2001).

\section{The Panel Data Models}

There are four possibilities and options when it comes to panel data regressions which are reviewed here under (Hsiao, 2007), (Frees, 2004). However, it should be noted that the series in this research is T 21 years while the cross-sectional unit $\mathrm{N}$ is 12 .

\section{The Fixed Effect Model}

The term "fixed effect" is due to the fact that although the intercept may differ among countries, each country does not vary overtime, that is time-variant. This is the major assumption under this model i.e. while the intercept are cross-sectional variant, they are time variant.

\section{Within-Group Fixed Effects}

In this version, the mean values of the variables in the observations on a given firm are calculated and subtracted from the data for the individual, that is;

$$
Y_{i t}-\hat{Y}_{i}=\sum_{1=2}^{k} \beta_{i}\left(X_{i j t}-X_{i j}\right)+\partial(t-\bar{t})+E_{i t}-\bar{E}_{i}
$$

And the unobserved effect disappears. This is known as the within-groups regression model.

\section{First Difference Fixed Effect}

In the first difference fixed effect approach, the first difference regression model, the unobserved effect is eliminated by subtracting the observation for the previous time period from the observation for the current time period, for all time periods. For individual $i$ in time period $t$ the model may be written as:

$$
Y_{i t}=\beta_{i}+\sum_{1=2}^{k} \beta_{j} X_{i j t}+\partial t+\infty_{i}+E_{i t}
$$

For the previous time period, the relationship is

$$
Y_{i t}=\beta_{i}+\sum_{1=2}^{k} \beta_{j} X_{i j t}-1+\partial(t-1)+\infty_{i}+E_{i t-1}
$$

Subtracting (7) from (8) one obtains

$$
\Delta Y_{i t}=\beta_{i}+\sum_{1=2}^{k} \beta_{j} \Delta X_{i j t}+\partial t+E_{i t}-E_{i t-1}
$$

and again unobserved heterogeneity has disappeared. 


\section{Random Effect Model}

Another alternative approach known as the random effects regression model subject to two conditions provides a solution to a problem in which a fixed effect regression is not an effective tool when the variables of interest are constant for each firm and such variables cannot be included.

The first condition is that it is possible to treat each of the first unobserved $Z_{p}$ variables as being drawn randomly from a given distribution. This may well be the case if the individual observations constitute a random sample from a given population.

$$
\text { If } Y_{i t}=\beta_{j}+\sum_{1=2}^{k} \beta_{j} X_{i j t}+\partial t+\infty_{i}+E_{i t}=\beta_{i}+\sum_{1=2}^{k} \beta_{j} X_{i j t}+\partial t+\mu_{i t} . \text { ( }
$$

where: $\mu_{i t}=\infty_{i}+E_{i t}$.

The unobserved effect has been dealt with by subsuming it into the disturbance term. The second condition is that the $Z_{p}$ variables are distributed independently of all the $X_{j}$ variables. If this is not the case, $\infty$, and here $\mu$, will not be uncorrelated with $X_{j}$ variables and the random effects estimation will be biased and inconsistent.

\section{Results and Discussion}

This aspect of the paper presents the results of the data analysis and the interpretation of the results are also done. It begins with the descriptive analysis.

\section{Descriptive analysis}

The trend analysis of industrial sector growth, institutional quality and human capital are presented under this section. It begins with the summary of statistics.

Table 1: Summary of statistics

\begin{tabular}{|l|c|c|c|c|c|c|c|}
\hline & CORR & EXR & GOVEF & HC & INDGR & INF & K \\
\hline Mean & -0.568030 & 570.7195 & -0.692727 & 1.467867 & 19.16711 & 5.235606 & 18.85844 \\
\hline Median & -0.625000 & 494.4150 & -0.670000 & 1.433002 & 19.83549 & 3.200000 & 19.45454 \\
\hline Maximum & 0.180000 & 4524.158 & 0.160000 & 2.374476 & 37.44548 & 46.60000 & 42.03716 \\
\hline Minimum & -1.700000 & 0.064871 & -1.880000 & 1.041401 & 3.243096 & -3.100000 & -2.424358 \\
\hline Std. Dev. & 0.404207 & 810.9915 & 0.478670 & 0.294493 & 6.563693 & 6.392137 & 8.017716 \\
\hline Observations & 264 & 264 & 264 & 264 & 264 & 264 & 264 \\
\hline
\end{tabular}

Source: Author's Computation

The means of the two indicators of institutional quality in the ECOWAS are negative. Precisely control of corruption and government effectiveness are 0.568030 and -0.692727 respectively. This is an indication that there is poor quality of institutions in the ECOWAS. Human capital mean is 1.467867. Despite the fact that the value is positive, it is closer to the minimum than maximum. The industrial sector growth is also positive during the period under review. To be able to explore 
the position of individual countries of ECOWAS in this distribution, trend analysis of the countries are done for each of the variables. The result is presented in the following figures. These are done for individual country for each variable.

\section{Figure 1: Trends of Human Capital Index}

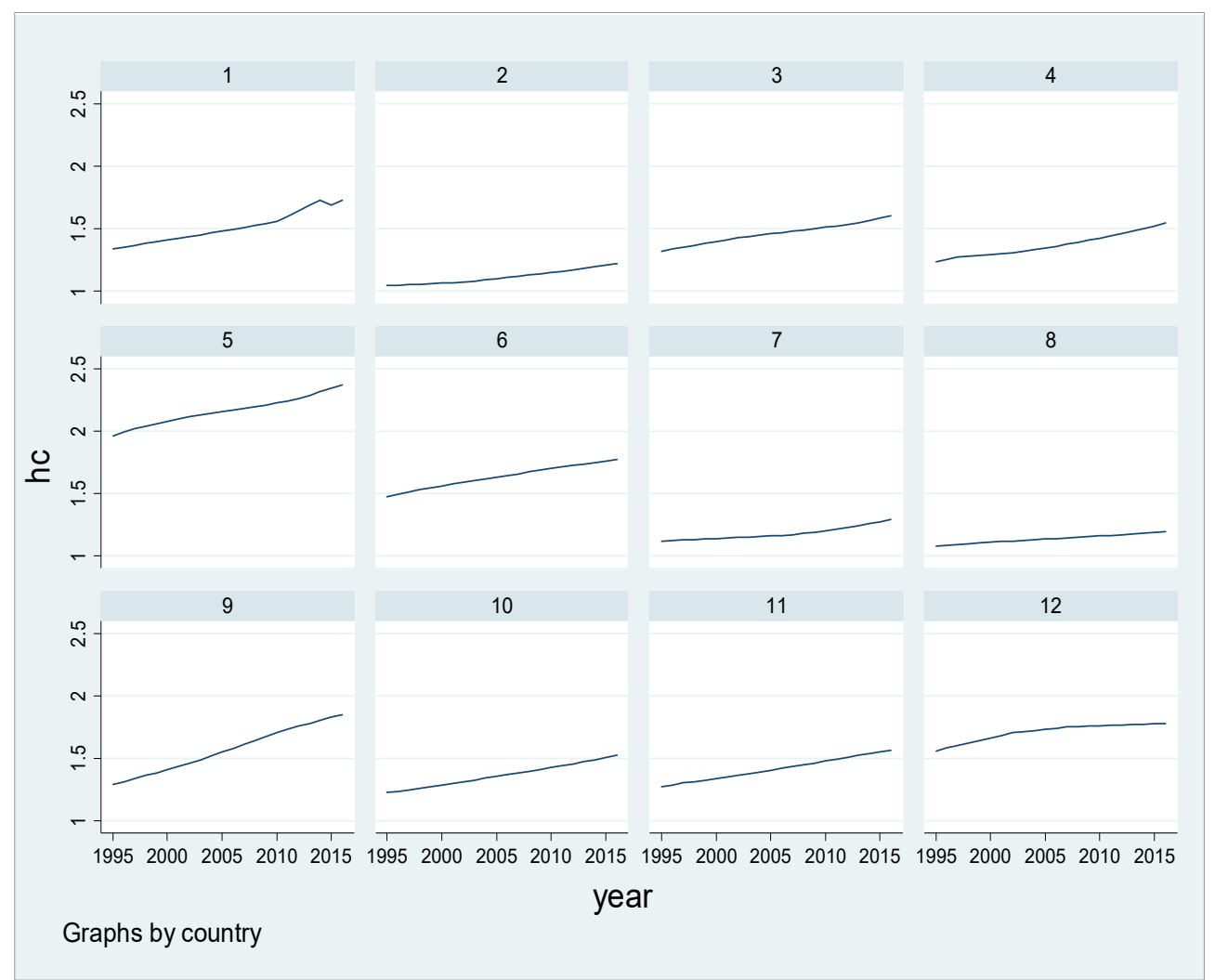

Key: Country 1-Benin, Country 2- Burkina Faso, Country 3-Ivory Coast, Country 4-Gambia, Country 5-Ghana, Country 6-Liberia, Country 7-Mali, Country 8-Niger, Country 9-Nigeria, Country 10-Senegal, Country 11-Serra Lone, Country 12-Togo

Source: Author's Computation

Figure 1 shows the trend of human capital index in the ECOWAS countries. Twelve out of the 15 member organization are covered in the study due to data availability but the countries represent about $98.5 \%$ of the entire GDP of the ECOWAS region. This is an indication that they can be used to assess the situation of human development index in the region. The trend shows that all the countries follow upward trend in terms of their human capital index. However, the scale of human capital is from 1 to 5 with point 1 the weakest level of human capital index and point 5 the strongest (World Bank, 2017). From all the countries in the ECOWAS, all their trends are below 
2 point, which signifies a weak human capital index for the region. Niger Republic and Mali have the weakest human capital index with value less 1.5. Ghana is the only country in the ECOWAS with the point that is greater than 2 hence, it is the nation with the highest level of human capital index in the ECOWAS sub-region.

\section{Figure 2: Trends of institutional quality index}

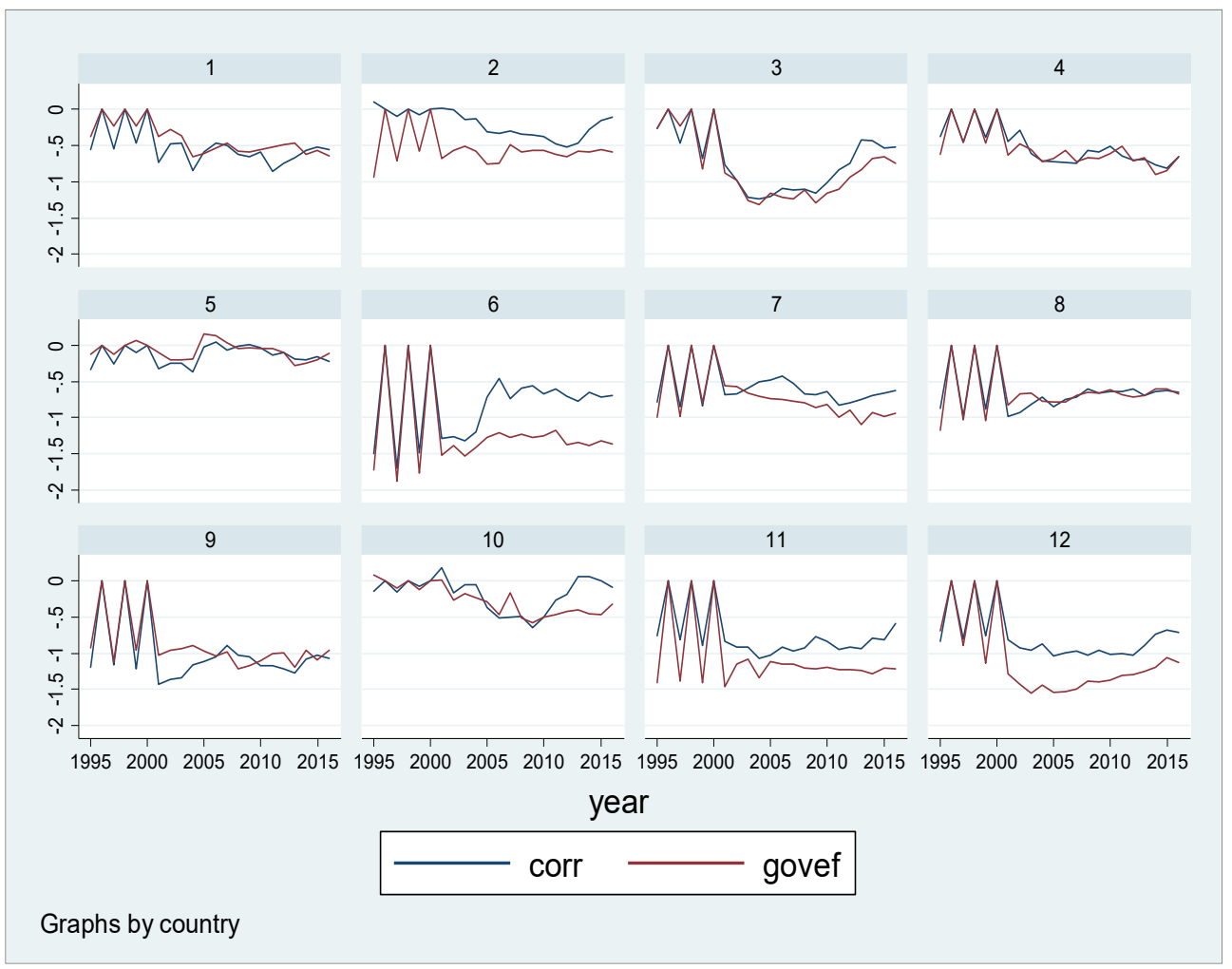

Key: Country 1-Benin, Country 2- Burkina Faso, Country 3-Ivory Coast, Country 4-Gambia, Country 5-Ghana, Country 6-Liberia, Country 7-Mali, Country 8-Niger, Country 9-Nigeria, Country 10-Senegal, Country 11-Serra Lone, Country 12-Togo

Source: Author's Computation

Control of corruption and government effectiveness indices are used to proxy institutional quality in this study. The index for both range from -2.5 to 2.5 with -2.5 showing weakest control of corruption and the most ineffective government. All the countries have negative and falling trends of both Control of corruption and government effectiveness. However, Ghana and Senegal do not have a pronounced falling trend like others. They both recorded positive trends along the period unlike others where negative and falling trend remain pronounced all through the period investigated. 
Figure 3: Trends of industrial growth

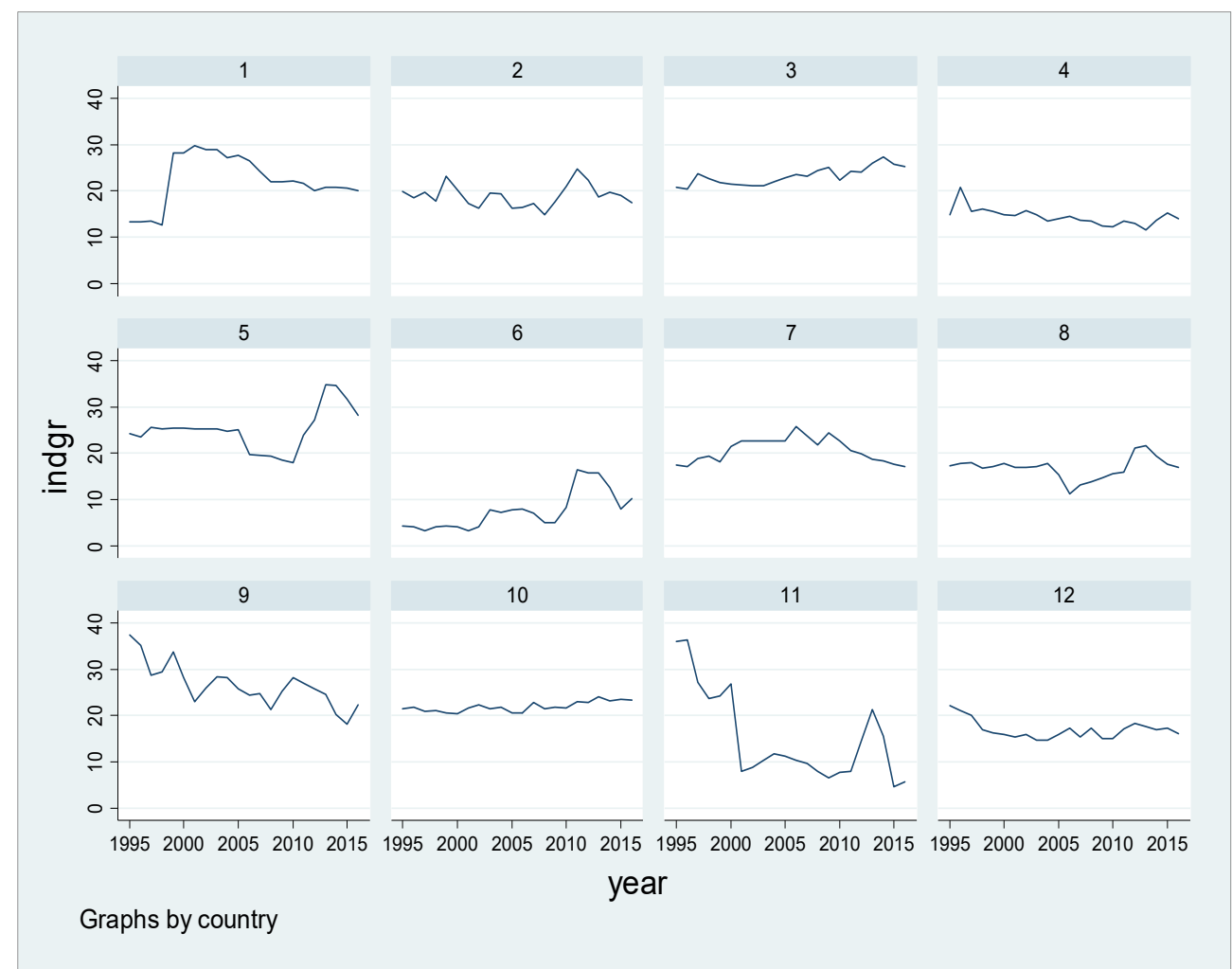

Key: Country 1-Benin, Country 2- Burkina Faso, Country 3-Ivory Coast, Country 4-Gambia, Country 5-Ghana, Country 6-Liberia, Country 7-Mali, Country 8-Niger, Country 9-Nigeria, Country 10-Senegal, Country 11-Serra Lone, Country 12-Togo

Source: Author's Computation

Figure 3 is a clear indication that the industrial growth in the ECOWAS has been unstable and in most of the countries it follows a downward trend movement. The downward trends are more pronounced in countries like Nigeria, Sierra Leone and Togo. Notwithstanding, some countries also witnessed upward trends during the period under review these countries are Ghana and Ivory Coast but what is common to all the countries is that recently all of them has been witnessing a downward trend in their industrial sector growths.

\section{Panel data estimation}

The panel data analysis investigates the impacts of institutional quality and human capital of the industrial growth in ECOWAS. The result from the panel regression using fixed effect method is presented in table 2 . 
Table 2: Panel data estimation (Fixed effects results)

\begin{tabular}{|c|l|}
\hline Variables & ECOWAS \\
\hline Log of Human Capital index & .364065 \\
& $(.3858542)$ \\
\hline Control of corruption & -.0033205 \\
& $(.1112019)$ \\
\hline Government effectiveness & .13185 \\
$(.1208996)$ \\
\hline Log of Economic growth & .0494585 \\
& $(.0269875)$ \\
\hline Log of Exchange rate & $-.0144387^{* *}$ \\
& $(.0013016)$ \\
\hline Log of Inflation rate & $-.0259483^{* * *}$ \\
$(.1210192)$ \\
\hline Log of capital & .0236834 \\
& $(.0563802)$ \\
\hline HAUSMAN test & 0.000 \\
\hline R square & 0.1469 \\
\hline Cross-sectional dependence test probability & $\operatorname{Pr}=0.9955$ \\
\hline
\end{tabular}

Source: Author's computation

Firstly, the results of the panel data show that the fixed effect results are suitable for all the analysis because the HAUSMAN test chi square statistics is significant at $5 \%$ therefore, the results presented on table 2 are the fixed effects version.

Secondly, the results show that human capital index in ECOWAS has not made any significant contribution to the industrial growth of the region. The coefficient of human capital index is .364065 . Although, it is positive, the coefficient is not statistically significant. This implies that levels of human capital development witnessed in the ECOWAS region during the period under review fail to contribute significantly to the growth of the industrial sector. The result supports the findings of (Unger, Rauch, Frese, \& Rosenbusch, 2011) where it was concluded that most developing countries in Africa are suffering from human capital deficiency and that this is the major reason their real sectors are backward.

The institutional quality is proxy with two variables namely; government effectiveness and control of corruption. The result from the panel data has also shown that their coefficients are -.0033205 and 0.13185 for control of corruption and government effectiveness respectively. Again, none of the two coefficients is statistically significant. Thus, it implies that institutional qualities in the ECOWAS have not promoted industrial growth during the period under review. The result follows the findings under the descriptive statistics where it was shown that for most of the countries in ECOWAS their institutional qualities indices are negative. This might account for the reason why they have not been able to exert significant impact on the growth of the industrial sector in the region. The findings are similar to that of Mehlum, Moene, \& Torvik, (2006) where it was established that government 
institutions in most of the countries in the Sub-Sahara Africa countries are witnessing economic development problem because they are weak.

However, other macroeconomic variables used as control factors in the model such as exchange rate and inflation rate have significant impacts on industrial growth in ECOWAS. The result shows that the parameter estimates of exchange rate in the panel model are -.0144387 and this is significant at $5 \%$. The meaning is that currency depreciation in ECOWAS is not helpful to the industrial sector growth. The reason for this might not be unconnected with the fact that the industrial sector of the ECOWAS largely depends on import for most of their raw materials and capital goods. Therefore, currency depreciation will only increase their cost of production. Comparing this result to previous studies' findings, it was discovered that this position is also shared by (Bleaney \& Greenaway, 2001), (Rodrik, 2008),(Jongbo, 2014). Although their study is on Sub-Sahara Africa SSA, yet they concluded that most of the real sectors of countries in the SSA are less capital intensive domestically and hence depends on importation for most of their capital goods and as a result of this exchange rate policy that will make import cheaper will encourage the growth of their real sectors.

Inflation rate on the other hand was shown to be an important determinant of industrial sector growth in the panel result. The coefficient is -.0259483 and significant at $5 \%$. This confirms that a rising inflation will affect the growth of the industrial sector adversely. It further justifies the position earlier that rising cost of production is inimical to the growth of the industrial sector of ECOWAS.

Moreover, other variables used in the model such as economic growth and capital formation failed to have significant impact on the growth of the industrial sector of the ECOWAS. It should be noted that the capital is proxy with gross fixed capital formation for the individual economy since there is no data on capital for industrial sector only. The implication of this is that the investment in the ECOWAS is less industrial sector driven.

\section{Conclusions}

Findings from the analysis have led to some conclusions that are very important for the relationship among human capital, institutional quality and industrial growth of the ECOWAS. Firstly, various literatures have shown that for the entire SSA to improve their levels of economic development and catch up with the developed economies, they will need to diversify their economies since most of them currently depend on primary export. ECOWAS as part of the SSA has been struggling with the problem of diversification and the reason has been the stunted growth of the industrial sector. This study concludes that the issue of human capital which was described as a major catalyst that can boost the industrial sector growth is not impacting significantly on the industrial sector in ECOWAS. The study has contributed to the existing literatures and theories on relevance of human capital in economic growth. Lucas model of endogenous growth model identified human capital as an important factor that drives growth. It is obvious from the conclusion of this study that the weak human capital in ECOWAS has contributed to the stunted industrial growth witnessed over the years in the region. 
Another conclusion from the study is that institutions in ECOWAS are not supporting the growth of the industrial sector. It is evident from the findings that both government effectiveness and control of corruption has failed to have impact on the industrial growth of the ECOWAS. The implication of this conclusion is that, for ECOWAS to record significant development in their industrial sector, their institutions must be improved. In addition, conclusion from this study has re-emphasized the need for strong institutions to support industrial sector growth. This has again contributed to the existing literatures on the relationship between institutions and growth as emphasized by the Rostow theory of economic development.

It has also been confirmed from the study that the industrial sector of ECOWAS is more affected by macroeconomic variables such as exchange rate and inflation rate. The study also concludes that currency devaluation might not promote or aid the growth of the industrial sector of the ECOWAS. In addition, as a region, rising inflation rate is another important factor that has been shown from the study as a factor that affects the growth of the industrial sector adversely. The relevance of macroeconomic variables in growth which was emphasized by the endogenous and the neoclassical growth models has been supported by the conclusion from this study

Finally, both economic growth and investment in the ECOWAS generally are not industrial sector-supportive. The investment in the ECOWAS is not influencing industrial growth significantly. This shows that the level of investment or physical capital generally in the ECOWAS is not adequate to promote the growth of industries. Again, as seen from the study, that economic growth of the ECOWAS is also not driven by the industrial sector.

It is recommended, therefore, that ECOWAS countries should work on promoting their human capital development aggressively in order to make it have significant influence on the growth of their industrial sector. Again, as shown in the study that the quality of institutions currently in the ECOWAS is not supportive of the industrial sector growth consequently, efforts should be made by the authorities in the ECOWAS to improve their institutional quality

\section{References}

Abubakar, A., Kassim, S. H., \& Yusoff, M. B. (2015). Financial development, human capital accumulation and economic growth: empirical evidence from the Economic Community of West African States (ECOWAS). Procedia-Social and Behavioral Sciences, 172, 96-103.

Ajide, K. B. (2014). Determinants of foreign direct investment in ECOWAS countries: The roles of governance and human capital. The Empirical Econometrics and Quantitative Economics Letters, 3(2), 61-74.

Bleaney, M., \& Greenaway, D. (2001). The impact of terms of trade and real exchange rate volatility on investment and growth in sub-Saharan Africa. Journal of development Economics, 65(2), 491-500.

Breitung, J., \& Das, S. (2005). Panel unit root tests under cross-sectional dependence. Statistica Neerlandica, 59(4), 414-433.

Choi, I. (2001). Unit root tests for panel data. Journal of international money and Finance, 20(2), 249-272. 
Desmet, K., Greif, A., \& Parente, S. L. (2020). Spatial competition, innovation and institutions: the Industrial Revolution and the Great Divergence. Journal of Economic Growth, 25(1), 1-35.

Dawson, J. W. (1998). Institutions, investment, and growth: New cross-country and panel data evidence. Economic inquiry, 36(4), 603-619.

Frees, E. W. (2004). Longitudinal and panel data: analysis and applications in the social sciences: Cambridge University Press.

Haltiwanger, J. C., Lane, J. I., \& Spletzer, J. (1999). Productivity differences across employers: The roles of employer size, age, and human capital. American Economic Review, 89(2), 94-98.

Hoechle, D. (2007). Robust standard errors for panel regressions with crosssectional dependence. The stata journal, 7(3), 281-312.

Hsiao, C. (2007). Panel data analysis-advantages and challenges. Test, 16(1), 122.

Jongbo, O. C. (2014). The impact of real exchange rate fluctuation on industrial output in Nigeria. Journal of Policy and Development Studies, 289(1849), 111.

Keho, Y. (2018). Manufacturing and Economic Growth in ECOWAS Countries: A Test of Kaldor's First Law. Modern Economy, 9(5), 897-906.

Lavallée, E., \& Roubaud, F. (2019). Corruption in the informal sector: evidence from West Africa. The Journal of Development Studies, 55(6), 1067-1080.

Mehlum, H., Moene, K., \& Torvik, R. (2006). Institutions and the resource curse. The economic journal, 116(508), 1-20.

$\mathrm{Ng}$, S., \& Perron, P. (2001). Lag length selection and the construction of unit root tests with good size and power. Econometrica, 69(6), 1519-1554.

Nguyen, V. (2020). Human capital, capital structure choice and firm profitability in developing countries: An empirical study in Vietnam. Accounting, 6(2), 127136.

Nurudeen, A., Karim, A., Zaini, M., \& Aziz, M. I. (2015). Corruption, political instability and economic development in the Economic Community of West African States (ECOWAS): is there a causal relationship? Contemporary economics, 9(1), 45-60.

Ranis, G. (1973). Industrial sector labor absorption. Economic Development and Cultural Change, 21(3), 387-408.

Rodrik, D. (2008). The real exchange rate and economic growth. Brookings papers on economic activity, 2008(2), 365-412.

Unger, J. M., Rauch, A., Frese, M., \& Rosenbusch, N. (2011). Human capital and entrepreneurial success: A meta-analytical review. Journal of business venturing, 26(3), 341-358. 